\title{
The quality of pasta versus rice is determining to control hunger and appetite: A comparative study of pasta and rice
}

\author{
Javier Marhuenda Hernández ${ }^{a, *}$, Raúl Arcusa Saura ${ }^{a}$, Ana Serna Oñate ${ }^{a}$, Desiree Victoria Montesinos ${ }^{b}$, \\ Maravillas Sánchez Macarro ${ }^{\text {, }}$, María Salud Abellán Ruiz ${ }^{b}$, Francisco Javier Quinde ${ }^{c}$, Alejandra Mariana \\ Rizo-Patrón ${ }^{\mathrm{C}}$, Francisco Javier López Román ${ }^{\mathrm{b}}$

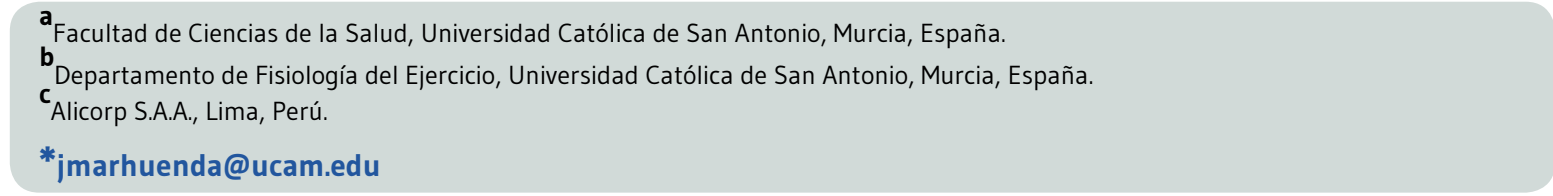
Assigned Editor: Itziar Abete-Goñi. Centro de Investigación en Nutrición, Universidad de Navarra. Pamplona, España.

Received: 20/03/2020; accepted: 29/04/2020; published: 25/06/2020 (**).

$(* *)$ Notice: This article has undergone a major modification after acceptance and publication in post-print. The original authors requested the incorporation of two new authors (FJQ and AMRP) who are salaried workers of the company that financed the study.

\section{KEYWORDS}

Nutritional

Physiological

Phenomena;

Appetite Regulation;

Appetite;

Satiation;

Satiety Response;

Visual Analog Scale;

Food;

Oryza;

Rice;

Pasta.
The quality of pasta versus rice is determining to control hunger and appetite: A comparative study of pasta and rice

Introduction: The aim of the present study was to evaluate if the pasta quality is decisive in controlling hunger and satiety compared with rice.

Material and Methods: $n=16$ ( 8 men, 8 women). The effect on appetite and satiety of two differentquality pastas and also rice was determined by repeated measuring. Subjects came on fasting and were evaluated at different times after the intake of product under investigation for 240 minutes, eaten an ad-libitum buffet and were evaluated again at minute 270 . Aspects related to satiety (hunger, satiety, fullness, and desire to eat) were evaluated by visual analog scale (VAS), overall appetite score (OAS), area under curve (AUC) and satiety quotient (SQ).

Results: The OAS reported by volunteers prior to the intake of products under investigation did not differ significantly, so baseline parameters did not bias later measurements. AUC after 60 minutes was higher after the intake of rice $(2,355 \pm 1,556 \% / \mathrm{min})$ compared with both types of pasta. On the other hand, similar values were obtained between the two types of pasta (Pasta $A=1,808 \pm 1,329 \% / \mathrm{min} ;$ Pasta $B=1,774 \pm 1,370 \% / \mathrm{min})$. Further, $A U C$ reported by volunteers after 240 minutes was higher after the intake of rice $(12,424 \pm 6,187 \% / \mathrm{min})$ compared with both types of pastas (Pasta $A=10,292 \pm 5,410 \% / \mathrm{min}$; Pasta $B=9,976 \pm 5,589 \% / \mathrm{min}$ ). In addition, $\mathrm{SQ}$ was lower for rice $(1.90 \pm 4.29 \% / \mathrm{kcal})$ than for both pastas (Pasta $A=4.73 \pm 4.95 \% / \mathrm{kcal}$; Pasta $B=4.40 \pm 5.14 \% \mathrm{kcal}$ ).

Conclusions: Both varieties of pasta showed higher satiety results than rice, with no significant difference between them. In addition, the difference between rice and pasta was greater within 60 minutes after ingestion. 
La calidad de las pastas frente al arroz es determinante en el control del hambre y el apetito: Estudio comparativo de pasta y arroz

\section{PLABRAS CLAVE}

Fenómenos

Fisiológicos de la Nutrición;

Regulación del Apetito;

Apetito;

Saciedad;

Respuesta de Saciedad;

Escala Visual Analógica;

Alimentos;

Oryza;

Arroz;

Pasta.

\section{RESUMEN}

Introducción: El objetivo del presente estudio fue evaluar si la calidad de la pasta es decisiva para controlar el hambre y la saciedad en comparación con el arroz.

Material y Métodos: $n=16$ ( 8 hombres, 8 mujeres). El efecto sobre el apetito y la saciedad de dos pastas de diferente calidad y también del arroz se determinó mediante mediciones repetidas. Los sujetos entraron en ayunas y fueron evaluados en diferentes momentos después de la ingesta del producto investigado durante 240 minutos, comieron un bufet ad libitum y fueron evaluados nuevamente en el minuto 270. Aspectos relacionados con la saciedad (hambre, saciedad, plenitud y deseo de comer) fueron evaluados por escala visual analógica (VAS), puntaje global de apetito (OAS), área bajo curva (AUC) y cociente de saciedad (SQ).

Resultados: La OAS informada por los voluntarios antes de la ingesta de productos bajo investigación no difirió significativamente, por lo que los parámetros de referencia no sesgaron las mediciones posteriores. El AUC después de 60 minutos fue mayor después de la ingesta de arroz $(2.355 \pm 1.556 \% / \mathrm{min})$ en comparación con ambos tipos de pasta. Por otro lado, se obtuvieron valores similares entre los dos tipos de pasta (Pasta $A=1.808 \pm 1.329 \% / m i n ;$ Pasta $B=1.774 \pm 1.370 \%$ / min). Además, el AUC informado por los voluntarios después de 240 minutos fue mayor después de la ingesta de arroz $(12.424 \pm 6.187 \% / \mathrm{min})$ en comparación con ambos tipos de pastas (Pasta $A=10.292 \pm 5.410 \% / \mathrm{min}$; Pasta $B=9.976 \pm 5.589 \% / \mathrm{min})$. Además, el $S Q$ fue menor para el arroz $(1,90 \pm 4,29 \% / \mathrm{kcal})$ que para ambas pastas (Pasta $A=4,73 \pm 4,95 \% / \mathrm{kcal} ;$ Pasta $B=4,40 \pm 5,14 \% / \mathrm{kcal}$ ).

Conclusiones: Ambas variedades de pasta mostraron resultados de saciedad más altos que el arroz, sin diferencias significativas entre ellos. Además, la diferencia entre arroz y pasta fue mayor dentro de los 60 minutos posteriores a la ingestión.

Marhuenda Hernández J, Arcusa Saura R, Serna Oñate A, Victoria Montesinos D, Sánchez Macarro M, Abellán Ruiz MS, Quinde FJ, Rizo-Patrón AM, López Román FJ. The quality of pasta versus rice is determining to control hunger and appetite: A comparative study of pasta and rice. Rev Esp Nutr Hum Diet. 2020; 24(3): 268-77. doi: 10.14306/renhyd.24.3.1034

\section{INTRODUCTION}

Obesity is caused by combination of factors that inevitably results in increased energy intake and/or decreased energy expenditure, leading to increased fat mass. The prevalence of obesity is associated with increased mortality, directly related to cardiovascular diseases, hypertension, diabetes mellitus, as well as certain types of cancer. Moreover, an increase of energy intake is a potential cause for the different symptoms associated with the development of obesity.
However, under-reporting of food intake is very common in developed countries ${ }^{1-5}$. This phenomenon seems to be greater in obese populations ${ }^{6-8}$, and people following restrictive diets ${ }^{8,9}$. In this context, later-term indicators of total energy intake (EIT) are relevant for identification of individual total food intake.

Regarding that phenomenon, overall appetite score (OAS) reflects subjective components of appetite control ${ }^{10}$, acting as objective food intake marker. OAS (defined by "hunger", "desire to eat" and "appetite for a meal") has been shown to be associated with energy intake $\mathrm{e}^{11-14}$. Similarly, 
OAS measurement after food intake also seems to be a reliable marker of early term energy intake ${ }^{15}$. Moreover, OAS measurement before and after meals may also reveal information about the satiating capacity of a certain food, which can be expressed as satiety quotient (SQ). The satiety efficiency of foods was originally introduced by Kissieff in 1984 for the measurement of the appetite reducing capacity of foods per unit of intake (for example, kcal, kj) ${ }^{16}$. This concept was extended taking into account the temporal effect of foods, leading to the calculation of $S Q$ over time ${ }^{17}$ which acts as marker of individual satiety capacity in response to a fixed meal test. Accordingly, the $S Q$ should be associated with later-term energy intake (lower $\mathrm{SQ}$ indicating a weaker satiating effect and, therefore, higher overall intake). The objective of the present study was to determine whether the composition of the ingredients that make up a pasta product has a decisive influence on satiety and hunger in healthy population compared with the intake of rice as control.

\section{MATERIAL AND METHODS}

A total of 16 volunteers ( 8 men and 8 women) were recruited for the study. Inclusion criteria were: age 35-50 years, body mass index (BMI) $25-35 \mathrm{~kg} / \mathrm{m}^{2}$ and absence of any disease at the beginning of the study. Exclusion criteria were: allergies or intolerances, chronic disease, consumption of drugs or medicines, a specific diet and changes in smoking habits during the study. The characteristics of the volunteers are shown in Table 1. After a full disclosure of the implications and restrictions of the protocol, volunteers were required to sign the informed consent.

Each volunteer went to the laboratory three times, with a week of separation between them. Each time, volunteers consumed one of the products under investigation. They

Table 1. Volunteers' characteristics.

\begin{tabular}{|c|c|}
\hline & Data \\
\hline Age & $37.1 \pm 9.0$ \\
\hline Height (cm) & $171.3 \pm 8.2$ \\
\hline Weight (kg) & $79.7 \pm 15.9$ \\
\hline Fat mass (kg) & $26.2 \pm 5.8$ \\
\hline Muscle mass (kg) & $54.4 \pm 9.9$ \\
\hline BMI (kg/m $\mathbf{2})$ & $28.5 \pm 2.6$ \\
\hline
\end{tabular}

were required to fast for 12 hours before each visit, and to avoid alcohol consumption and intense physical activity the day before the test. At the beginning of every intervention day, one of the products under study was served to the volunteers, who were instructed to eat the product during the following 15 minutes. After that, volunteers avoided food intake and intense physical or mental activity for the subsequent 4 hours (240 minutes). After this time, a buffet lunch was served. Volunteers were instructed to eat until they were comfortably satiated (ad-libitum). In order to interference during the measurement period, participants were isolated in a quiet area away from sensory distractions.

Nutritional value of the food served was determined by the software Dietsource v 3.0. Moreover, the food chosen by the volunteers was measured before and after the buffet lunch intake. Therefore, energy and macronutrients were determined for every volunteer from the quantitative measurement of food ingested.

The evaluation of satiety measured by the intake of energy adlibitum was carried out for each product under investigation, with all subjects consuming all three products. Sample size was chosen according to the scientific evidence available from other reproducible studies. Quantitative variables were evaluated by mean and standard deviation. Finally, ANOVA was performed for overall comparison among variables, using T-student test for paired analyses.

The nutritional composition of products under investigation is shown in Table 2.

Pasta products were made with a mixture of three different varieties of wheat known as "durum", "aestivum" and "reprocess" in different proportions, leading to a different composition for each pasta (Table 3). That composition was chosen in order to test whether the quality of pasta ingredients influences satiety and fullness. Reprocess wheat is the poorest quality wheat and is obtained from ground noodles or other wheat-based products. Meanwhile, durum and aestivum are high quality first grinding wheats, with very small amount of ash. Between these two varieties of superior quality wheat, it is worth noting that aestivum has better nutritional quality due to its higher dietary fiber content.

Visual analog scales (VAS) were used to evaluate OAS after the intake of every product under investigation. Volunteers reported their state of hunger, satiety and fullness on a $10 \mathrm{~cm}$ VAS by placing a vertical line on ascale that ranged, on the hunger scale, from "I have no hunger" to "I am the most hungry I have ever been"; on the satiety scale, from "I have no feeling of fullness" to "I'm as full as I've ever been"; on the fullness scale, from "I have no feeling of fullness" 
Table 2. Nutritional composition of products under investigation.

\begin{tabular}{|c|c|c|c|c|c|c|c|}
\hline Proximate & Units & Rice & Pasta A & Pasta B & Wheat Durum & Wheat Aestivum & Wheat Reprocess \\
\hline Energy & kcal & 374 & 343.43 & 340.92 & 339 & 342 & 371 \\
\hline Water & $\mathrm{g}$ & 9.86 & 9.17 & 10.28 & 10.94 & 9.57 & - \\
\hline Protein & $g$ & 7.51 & 11.91 & 13.64 & 13.68 & 11.31 & 13.04 \\
\hline Total Lipid (fat) & g & 1.03 & 1.85 & 2.41 & 2.47 & 1.71 & 2.47 \\
\hline Carbohydrate & $g$ & 80.89 & 74.86 & 71.34 & 71.13 & 75.9 & 71.13 \\
\hline Sugars, total & g & 0.3 & 0.49 & 0.16 & - & 0.41 & - \\
\hline Ash & g & 0.71 & 1.11 & 0.00 & - & 1.52 & - \\
\hline Fiber & $\mathrm{g}$ & 1.8 & 9.13 & 0.19 & - & 12.2 & - \\
\hline
\end{tabular}

to "I have the greatest feeling of fulfillment I've ever had" and on the prospective food consumption scale (PFC) from "I have no desire to eat any food" to "I have the greatest desire to eat any food I've ever had". OAS was calculated as the average of the four individual scores: (satiety + fullness + (100 - PFC) + (100 - hunger) ) / 4.

VAS for each of the evaluated components of appetite, were completed by volunteers in the following times: before and immediately after the intake of product under investigation, and at 10", 20", 30", 40", 50", 60", 120", 180", 240" (immediately before ad-libitum meal) and 270" post-intake of foods under investigation (immediately after consumption of ad-libitum meal) ${ }^{18,19}$ (Figure 1).

Overall Appetite sensation (OAS) was calculated at every measurement interval, and the change in OAS was calculated as the difference between OAS baseline and OAS of each subsequent measurement using the following formula:

$$
\text { Decrease of appetite }=O A S_{\text {pre-intake }}-O A S_{\text {post-intake }}
$$

In which the average OAS 60 minutes post-intake was represented by the area under curve (AUC) at OAS (time 0 , $10,20,30,40,50$ y 60).

In the measurement of OAS, the area under the curve was calculated by summarizing the mean scores of pairs of

Table 3. Percentage of different wheat in each type of pasta.

\begin{tabular}{c|c|c|c} 
& Durum & Aestivum & Reprocess \\
\hline Pasta A & $20 \%$ & $73 \%$ & $7 \%$ \\
\hline Pasta B & $94 \%$ & - & $6 \%$ \\
\hline
\end{tabular}

adjacent time points and then calculating a weighted mean (weighted by the time difference of two time points). AUC was measured by the area under the curve of time course of OAS from minute 0 to 60 post-intake of product.

Satiety evaluation, using VAS was carried out for each product in every volunteer who attended the present research.

\section{Long term satiety}

The later-term effect on satiety of a food was determined from VAS, and the energy composition of products contained in the ad-libitum food consumption test, using the formula of $S Q$.

$\mathrm{SQ}$ was calculated by the subtraction of the value "desire to eat" before the intake of the product under study, minus the average of "desire to eat" in the 60 minutes after intake of the product. This difference was divided by the energy values of the ingested ad-libitum food. By convention, the result of $\mathrm{SQ}$ is multiplied by 100 to obtain a more manageable range of values. Therefore, the resulting formula was:

$$
\begin{aligned}
& \mathrm{SQ}(\mathrm{mm} / 100 \mathrm{kcal})=\text { Decrease of appetite (defined as: } \text { ) / Energy of } \\
& \mathrm{OAS}_{\text {pre-intake }}-\text { Average } \mathrm{OAS}_{60 \text { minutes post-intake }} \text { products under investigation (kcal) } 100 \\
& \text { products }
\end{aligned}
$$

Fullness factor (FF) was calculated from the nutrient content of each food by the following formula:

$$
\begin{gathered}
\mathrm{FF}=\operatorname{MAX}\left(0.5, \operatorname{MIN}\left(5.0,41.7 / \mathrm{CAL}^{0.7}+0.05 * \mathrm{PR}+6.17 \mathrm{E}-4\right.\right. \\
\left.\left.* \mathrm{DF}^{3}-7.25 \mathrm{E}-6^{*} \mathrm{TF}^{3}+0.617\right)\right)
\end{gathered}
$$

Where: CAL is total calories per $100 \mathrm{~g}$ (30 minimum), PR is grams protein per $100 \mathrm{~g}$ (30 maximum), DF is grams of dietary fiber per $100 \mathrm{~g}$ (12 maximum), TF is grams of total fat per $100 \mathrm{~g}$ (50 maximum). 
Figure 1. Chronology of EVA scale and appetite test after energy consumption ad-libitum.

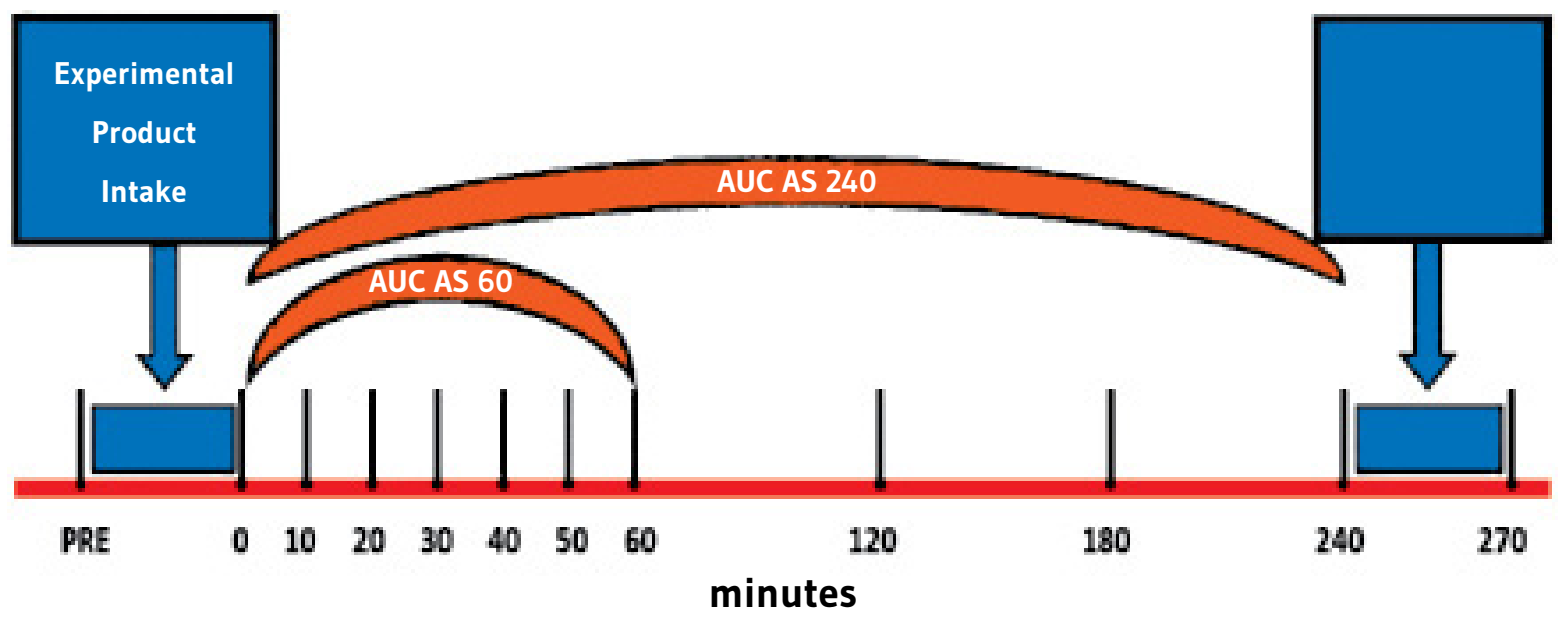

\section{RESULTS}

OAS prior to the intake of the products under investigation did not show significant differences between the products $(p<0.05)$. Therefore, volunteers began each interventional session at the same conditions (appetite sensation), which led to more reliable results (Figure 2).

As commented before, AUC includes the area above baseline of OAS. It was observed that AUC of OAS from immediate post-intake to instant 60 minutes post-intake was higher for rice $(2,355 \pm 1,556 \% \mathrm{x} / \mathrm{min})$ compared with both pastas. In contrast, both types of pasta induced a similar AUC with no statistically significant differences (Pasta $A=1,808 \pm 1,329 \% \min ;$ Pasta $B=1,774 \pm 1,370 \% / \mathrm{min}$ ) (Figure 3).

Performing statistical comparison, differences in appetite between products were significant $(p<0.05)$. In fact, rice showed higher AS than both varieties of pasta, while differences between both types of pasta were minimum ( $p>0.05$ ) (Figure 3). Moreover, the average OAS 60 minutes after the intake of rice $(39.3 \pm 25.9 \%)$ was higher for both pastas. On the other hand, both varieties of pasta showed similar ( $p>0.05$ ) AS (Pasta $A=30.1 \pm 22.1 \%$; Pasta $B=29.6 \pm 22.8 \%$ ) (Figure 2).
Figure 2. Appetite sensation (\%) of the subjects at baseline, at minute 60 and after ad-libitum intake. - * and ** represent statistically significant differences $(p<0.05)$.

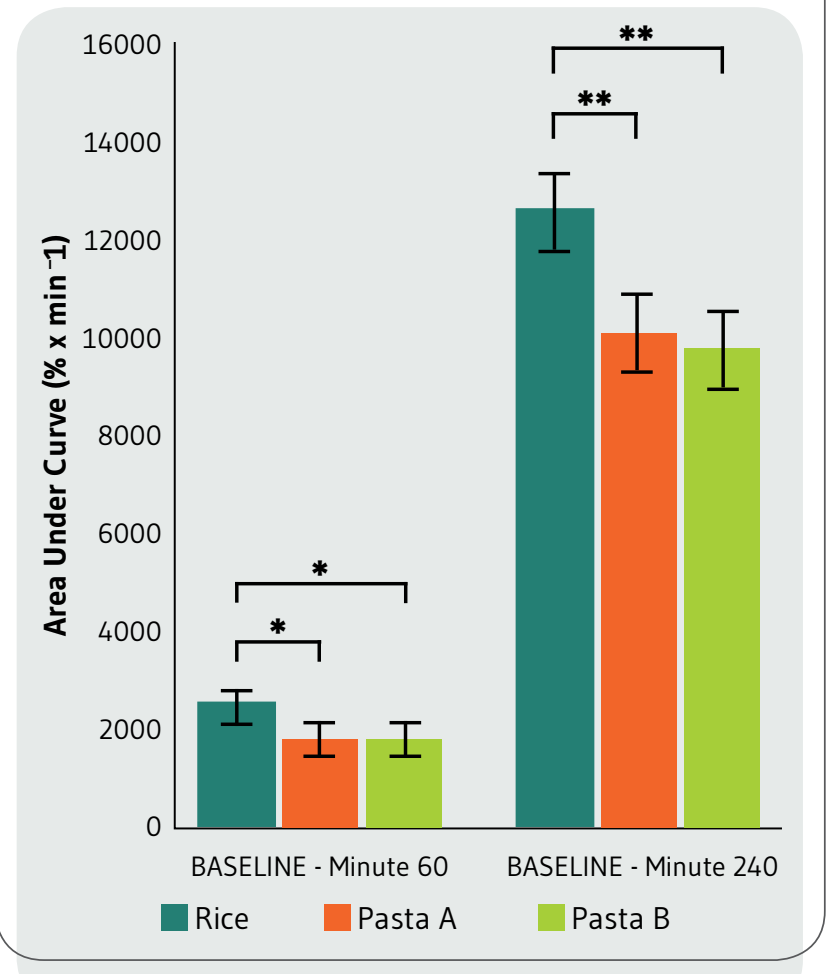


Figure 3. Area under the curve representing the evolution of appetite sensation (\% $\mathrm{x}$ min), comparing immediately postintake with instant 60 minutes ${ }^{*} p<0,003$, instant 240 minutes ${ }^{* *} p<0,01$.

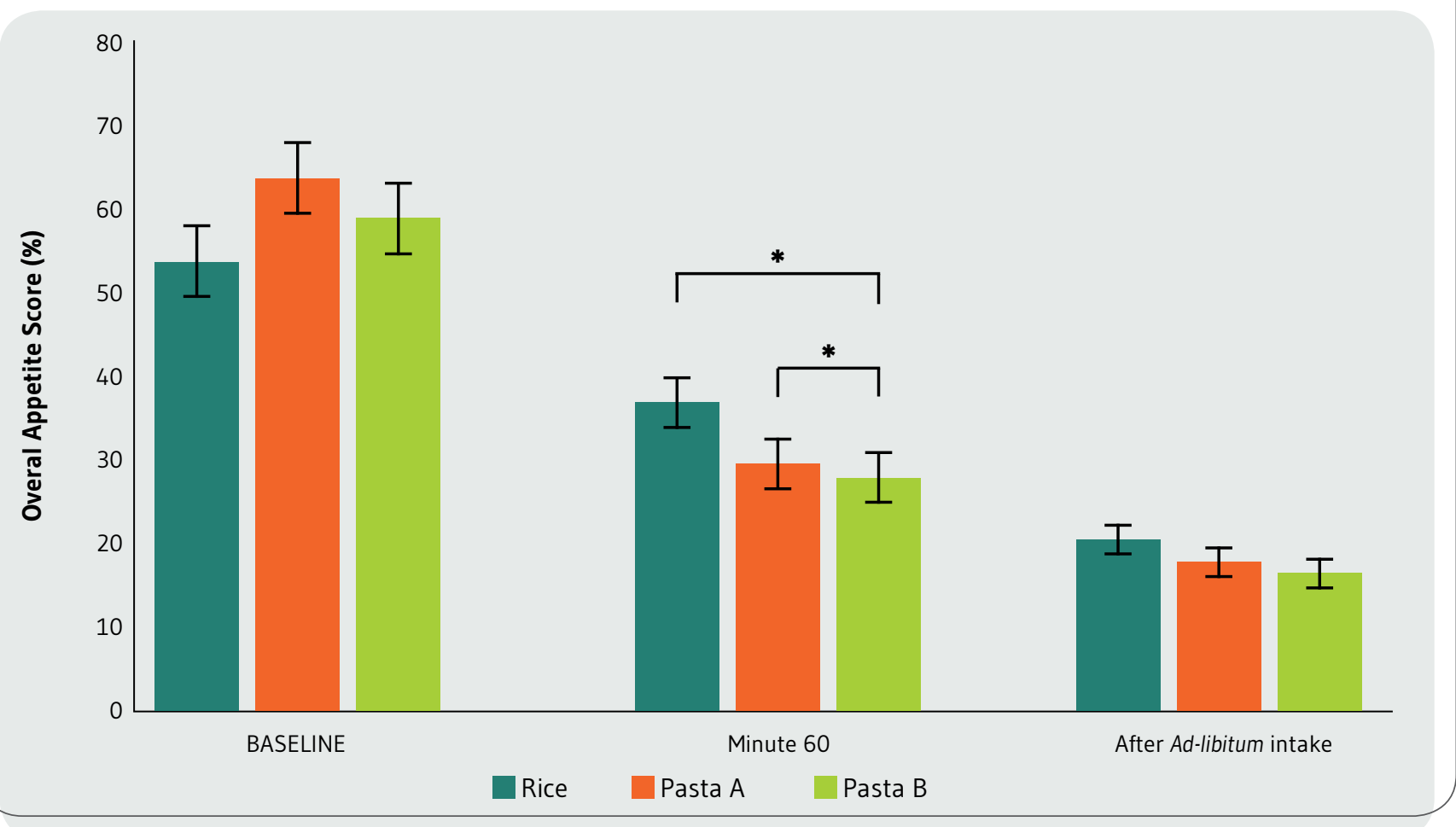

Moreover, significant differences were observed between different products under study $(p<0.05)$. In fact, rice consumption showed lower reduction in OAS than both varieties of pasta $(p<0.05)$. Meanwhile, no differences were observed between the varieties of pasta $(p>0.05)$ (Figure 4).

It was observed that AUC evolution of OAS from immediate post-intake to instant 240 post-intake was higher after rice intake $(12,424 \pm 6,187 \% \mathrm{x} / \mathrm{min})$ compared with both types of pasta $(p<0.05)$, with no significant differences ( $p>0.05)$ between the pastas (Pasta $A=10,292 \pm 5,410 \% x / m i n$; Pasta $B=9,976 \pm 5,589 \% x / m i n$ ) (Figure 3 ).

The statistical analysis showed similar values to those observed for early assessment of OAS, while rice intake showed greater AUC compared to both pastas $(p<0.05)$. AS observed before, there were no statistically significant differences in AUC values between the intake of both types of pasta. Therefore, early and later values indicate that OAS after 240 minutes from the intake of products under investigation is greater after the intake of rice than pasta.

OAS was measured after ad-libitum intake, showing no significant differences after the intake of rice or pasta $(p=0.52)$. Therefore, volunteers were satiated after ad-libitum intake, regardless of the type of product administered (Figure 2).

Energy consumption was measured during and after adlibitum intake. It can be noted that the intake of rice led to the highest energy consumption during ad-libitum intake $(787 \pm 196 \mathrm{kcal})$ compared with both types of pasta $(p<0.05)$. Furthermore, the intake of each pasta showed similar energy consumption after ad-libitum lunch (Pasta $A=700 \pm 150$ kcal; pasta $B=691 \pm 163 \mathrm{kcal}$ ) (Figure 5).

As it can be observed in the Figure 6, rice showed the lowest SQ $(1.90 \pm 4.29 \% / \mathrm{kcal})$. However, both types of pasta showed very similar SQ (Pasta $A=4.73 \pm 4.95 \% / \mathrm{kcal}$; Pasta $B=4.40 \pm$ $5.14 \% / \mathrm{kcal})$.

The statistical comparison revealed significant differences between the different products under study $(p<0.05)$. In fact, rice intake led to lower $S Q$ than pasta while no differences between pastas were observed, indicating that satiating capacity of both types of pasta is greater than rice, while there are no differences between pastas. 


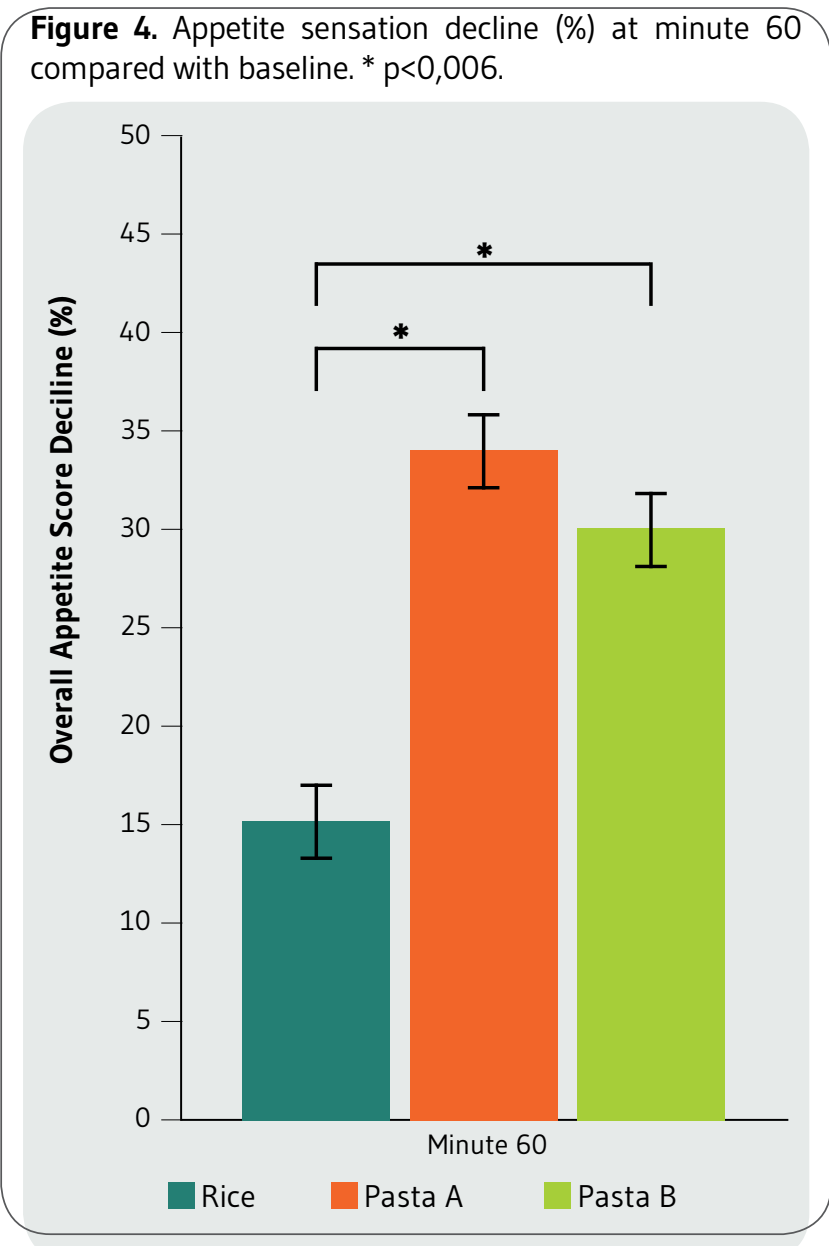

Therefore, it was observed that rice was the food with lower FF (1.66) while both types of pasta showed higher and very similar FF (Pasta $A=2.38$; Pasta $B=2.2$ ). Therefore, rice consumption showed poor fullness sensation compared with both pasta products $(p<0.05)$.

\section{DISCUSSION}

The main objective of the present study was to evaluate the influence on hunger and satiety of wheat quality of two different pastas compared with rice-control. The main finding of the present research was the lowest AUC of OAS from baselines to minute 60 post-intake showed by pasta and not for rice as placebo. The present study confirms the findings of other study, correlating the $S Q$ obtained after a $733 \mathrm{kcal}$ breakfast with ad-libitum intake ${ }^{20}$. These authors also evaluated the desire to eat, hunger and fullness every 10 minutes during the first hour. One of the main differences with the present study is that participants completed food reports for 3 days after the study.

In the present study, rice showed the minor satiating capacity with respect to both pastas and, consequently, led to greater energy consumption during ad-libitum intake. Moreover, differences observed between the intake of both types of pasta were not statistically significant ( $p>0.05$ ). This could be explained by their similar macronutrients content, as it can be observed in another study comparing satiety between two varieties of rice ${ }^{18}$. The results of the present study are not in accordance with those obtained in a study using the satiety index (SI) of 38 food types using bread as reference food, which reported a higher SI for white rice (138 \pm 31$)$ with respect to white pasta $(119 \pm 35)^{21}$.

Figure 5. Average energy consumption (kcal) consumed during ad-libitum lunch after the intake of each pasta and rice. ${ }^{*} p<0,05$.

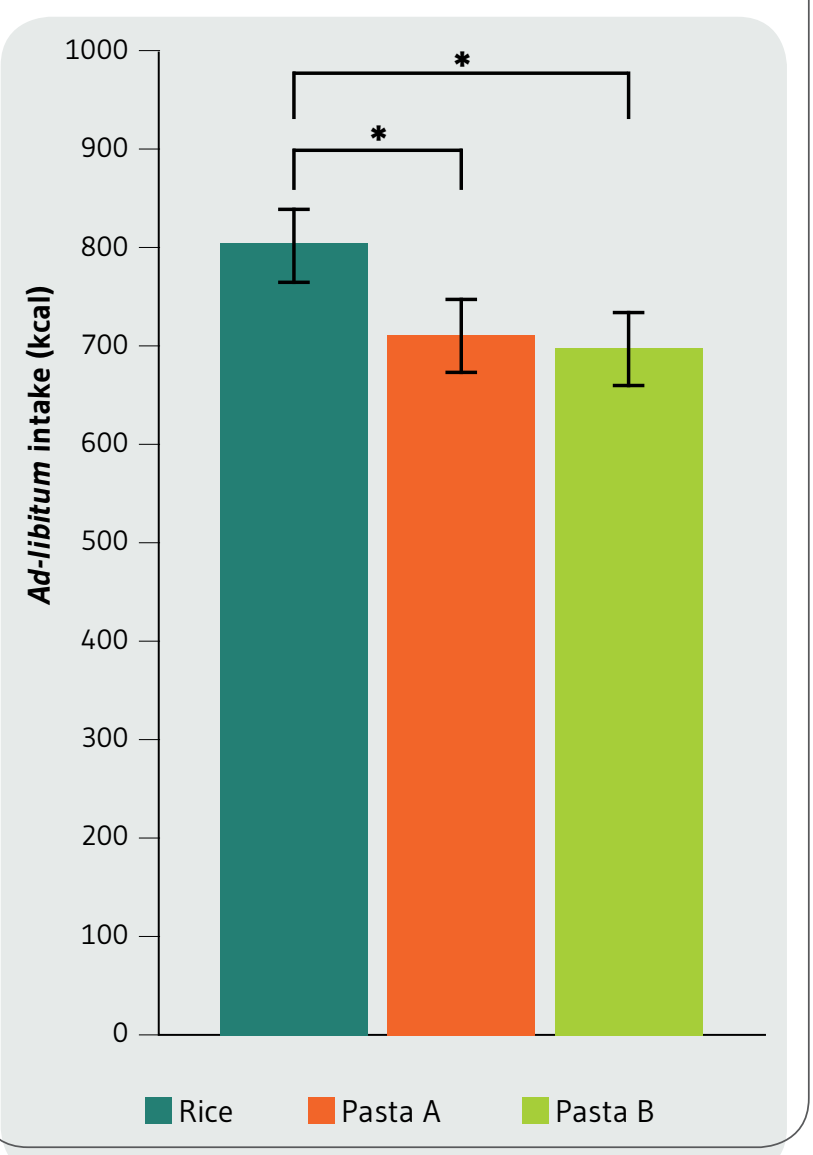


Figure 6. Satiety quotient $(\% / \mathrm{kcal}) * \mathrm{p}<0.05$ for each product.

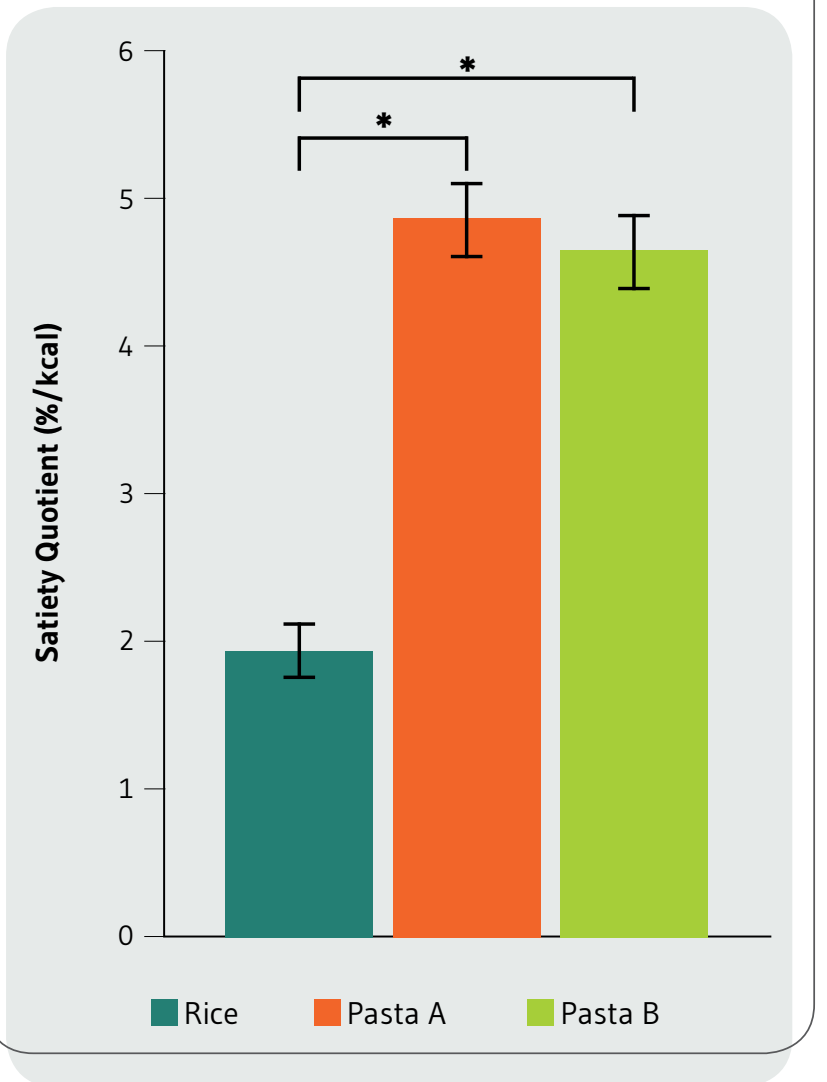

A secondary finding of the present study was the $S Q$, which revealed to be higher in pastas than in rice. The convenience of $S Q$ in the present study could be related to ad-libitum intake in the following 3 hours, considered as regular time periods between meals. Moreover, satiety -being defined as the interval between meals as a function of elapsed timecan be used to predict the next feeding episode ${ }^{22}$. Similar studies have reported satiating capacity of potato, rice and pasta, containing similar amounts of carbohydrates. In a recent study, VAS was determined every 30 minutes from baseline until 3 hours post-intake. The results confirmed greater satiety capacity for potato compared with rice and pasta, but no significant differences were observed between the latter two foods ${ }^{23}$. This greater satiating capacity could be explained by the higher water content and lower energy density of potato compared with rice and pasta, which leads to greater volume of ingested food that could cause a greater gastric distension and subsequent increase in satiety ${ }^{24}$. However, a limitation of that study was the lack of an ad-libitum lunch after the intake of the tested foods. Meanwhile, another study reported similar results for a total of 38 foods, showing higher SI for potatoes $(323 \pm 51)$ than for white rice and white pasta ${ }^{21}$.

The results of the presents research suggest an inverse correlation between $\mathrm{SQ}$ and caloric content of the ad-libitum lunch. However, other studies comparing solid and liquid food did not reported similar correlation ${ }^{21,25,26}$. Differences observed in that study can be explained by the short time between consumption of the study foods and ad-libitum intake, which could be insufficient for an influence on hunger or fullness.

Various factors have been reported to influence the satiating effect of foods, such as palatability, weight and volume of food, macronutrient composition and energy density. Especially, the great effect of energy density is inversely proportional to the satiety of foods, what seems to confirm that low energy foods have higher fiber, volume and weight content, leading to increased satiating capacity ${ }^{5}$. In the present research, different fiber content in pastas could give rise to certain advantages in terms of prevention of some chronic diseases such obesity, metabolic syndrome, type2 diabetes, cardiovascular diseases, or different types of cancer. Advantages include improving intestinal function, lowering LDL cholesterol and postprandial glucose, reducing the risk of certain cancers such as colon cancer or helping to lose weight ${ }^{27}$.

Another marker used for the assessment of satiety was the Gl. In fact, the great satiating capacity of pasta can be explained by the higher $\mathrm{Gl}$ found for pasta and not rice (73 vs. 49$)^{28}$. However, these data are not consistent with those observed in other studies, that found no relationship of the GI of foods, reporting similar results for carbohydrate quantities based on potato, rice and pasta cooked in different ways ${ }^{29,30}$. Other study reported similar values for energy intake during ad-libitum lunch and satiety; however, differences were observed in blood markers such as glucose, insulin, ghrelin and glucagon peptide-1 (GLP-1) ${ }^{31}$. The differences could be explained considering meals as a combination of different nutrients, giving rise to a particular value of $\mathrm{Gl}$. Therefore, GI may not be relevant for predicting satiety or later energy intake if a meal is composed by a combination of foods.

Moreover, it should be kept in mind that the particular experimental methodology employed is crucial, many studies use different procedures ${ }^{32}$. Due to the differences observed in the scientific literature (different experimental designs, types of subjects, timing of meals and types of foods) this may be useful for the emergence of an apparent consensus between outcomes. 


\section{CONCLUSIONS}

The intake of foods under study with similar macronutrients content, reported higher satiety quotient and stronger decrease in the appetite sensation for pastas compared with rice. However, there were no differences observed between pastas. This decrease in appetite sensation gave rise to a lower caloric intake in a subsequent ad-libitum meal. This reduction on the food intake could favor weight loss in overweight and obese population leading to health benefits.

\section{AUTHORS' CONTRIBUTIONS}

JMH, RAS and ASO developed the clinical study.

DVM, MSAR and FJLR designed the study and performed the clinical analysis.

JMH, RAS and FJLR wrote the present manuscript.

FJQ and AMRP have manufactured the products under study, based on technological criteria.

\section{FUNDING}

This research has been financed by Alicorp S.A.A.

\section{COMPETING INTERESTS}

FJQ and AMRP are salaried workers of the company that financed the study (Alicorp S.A.A.). The rest of the authors state that there are no conflicts of interest in preparing the manuscript.

\footnotetext{
$\longrightarrow$

REFERENCES

(1) Westerterp K, Verboeket-va de Vene W, Meijer G, Hoorten F. Self-reported intakes as a measure for energy intake. A validation against doubly labelled water. Obes Eur. 1991; 91: 17-22.
}

(2) Pannemans DL, Westerterp KR. Estimation of energy intake to feed subjects at energy balance as verified with doubly labelled water: a study in the elderly. Eur ] Clin Nutr. 1993; 47(7): 490-6.

(3) Johnson RK, Goran MI, Poehlman ET. Correlates of over- and underreporting of energy intake in healthy older men and women. Am J Clin Nutr. 1994; 59(6): 1286-90.

(4) Buhl KM, Gallagher D, Hoy K, Matthews DE, Heymsfield SB. Unexplained Disturbance in Body Weight Regulation. Diagnostic Outcome Assessed by Doubly Labeled Water and Body Composition Analyses in Obese Patients Reporting Low Energy Intakes. J Am Diet Assoc. 1995; 95(12): 1393-400.

(5) Schoeller DA. Limitations in the assessment of dietary energy intake by self-report. Metabolism. 1995; 44(Suppl. 2): 18-22.

(6) Lichtman SW, Pirsarska K, Bermna ER, Pestone M, Dowling H, Offenbacher $E$, et al. Discrepancy between self-reported and actual caloric intake and exercise in obese subjects. $\mathrm{N}$ Engl ] Med. 1992; 327(27): 1893-8.

(7) Heitmann BL. Dietary underreporting by obese individuals - is it specific or non-specific?. BMJ. 1995; 311(7011): 986-9.

(8) Lafay L, Basdevant A, Charles MA, Vray M, Balkau B, Borys $J M$, et al. Determinants and nature of dietary underreporting in a free-living population: The Fleurbaix Laventie Ville Sante (FLVS) study. Int ] Obes. 1997; 21(7): 567-3.

(9) Asbeck I, Mast M, Bierwag A, Westenhöfer J, Acheson K, Müller $M$. Severe underreporting of energy intake in normal weight subjects: use of an appropriate standard and relation to restrained eating. Public Health Nutr [Internet]. 2002; 5(05): 683-90. Available from: http://www.journals.cambridge.org/ abstract_S1368980002000915

(10) Stubbs RJ, Hughes DA, Johnstone AM, Rowley E, Reid C, Elia M, et al. The use of visual analogue scales to assess motivation to eat in human subjects: a review of their reliability and validity with an evaluation of new hand-held computerized systems for temporal tracking of appetite ratings. $\mathrm{Br}$ ] Nutr [Internet]. 2000; 84(04): 405. Available from: http://www.journals. cambridge.org/abstract_S0007114500001719

(11) Mattes R. Hunger ratings are not a valid proxy measure of reported food intake in humans. Appetite. 1990; 15(2): 103-113.

(12) Hulshof T, De Graaf C, Weststrate J. The effects of preloads varying in physical state and fat content on satiety and energy intake. Appetite. 1993; 21(3): 273-86.

(13) Barkeling B, Rossner S, Sjoberg A. Methodological studies on single meal food intake characteristics in normal weight and obese men and women. Int J Obes Relat Metab Disord [Internet]. 1995; 19(4): 284-90. Available from: http://www. ncbi.nlm.nih.gov/pubmed/7627254

(14) Porrini M, Crovetti R, Testolin G, Silva S. Evaluation of satiety sensations and food intake after different preloads. Appetite. 1995; 25(1): 17-30.

(15) Flint A, Raben A, Blundell JE, Astrup A. Reproducibility, power and validity of visual analogue scales in assessment of appetite sensations in single test meal studies. Int J Obes. 2000; 24(1): 38-48.

(16) Kissileff HR. Satiating efficiency and a strategy for conducting food loading experiments. Neurosci Biobehav Rev. 1984; 8(1): 129-135

(17) Green SM, Delargy HJ, Joanes D, Blundell JE. A Satiety Quotient: A Formulation to Assess the Satiating Effect of Food Biopsychology Group, Department of Psychology, University of 
Leeds Department of Statistics, University of Leeds. Appetite. 1997; 29(3): 291-304.

(18) Wang XS, Neill MO, Thomas W, Slavin J. White and Brown Rice are Equally Satiating and More Satiating than Glucose Beverage. J Obes Weight Loss Ther [Internet]. 2013; 3(202): 2. Available from: http://www.omicsgroup.org/journals/whiteand-brown-rice-are-equally-satiating-and-more-satiatingthan-glucose-beverage-2165-7904.1000201.php?aid=21268

(19) Klosterbuer AS, Thomas W, Slavin JL. Resistant starch and pullulan reduce postprandial glucose, insulin, and GLP-1, but have no effect on satiety in healthy humans. J Agric Food Chem [Internet]. 2012; 60(48): 11928-34. Available from: http:// www.embase.com/search/results? subaction=viewrecord $\& \mathrm{fr}$ om=export\&id=L366213766\%0Ahttp://dx.doi.org/10.1021/ jf303083r\%0Ahttp://bj7rx7bn7b.search.serialssolutions.com? sid=EMBASE \& issn=00218561\&id=doi:10.1021\%2Fjf303083r \&atitle=Resistant+starch+and+pullu

(20) Drapeau V, King N, Hetherington M, Doucet E, Blundell J, Tremblay A. Appetite sensations and satiety quotient: Predictors of energy intake and weight loss. Appetite. 2007; 48(2): 159-66.

(21) Holt RD, Pacala SW, Smith TW, Liu J. A satiety index of common foods. Eur ] Clin Nutr [Internet]. 1995; 49(June 2014): 67590. Available from: http://www.ncbi.nlm.nih.gov/entrez/ query.fcgi? cmd=Retrieve \&db=PubMed\&dopt=Citation\&li st_uids $=2102823$

(22) García-Flores CL, Martínez Moreno AG, Beltrán Miranda CP, Zepeda-Salvador AP, Solano Santos LV. Saciación vs. saciedad: Reguladores del consumo alimentario. Rev Med Chil. 2017; 145(9): 1172-8.

(23) Zhang Z, Venn BJ, Monro J, Mishra S. Subjective Satiety Following Meals Incorporating Rice, Pasta and Potato.
Nutrients. 2018; 10(11): 1-10.

(24) Clinical D, Centre N, Hospital A. Energy density and its role in the control of food intake. 1996; 153-74.

(25) Almiron-Roig E, Flores SY, Drewnowski A. No difference in satiety or in subsequent energy intakes between a beverage and a solid food. Physiol Behav. 2004; 82(4): 671-7.

(26) Tsuchiya A, Almiron-Roig E, Lluch A, Guyonnet D, Drewnowski A. Higher satiety ratings following yogurt consumption relative to fruit drink or dairy fruit drink. J Am Diet Assoc. 2006; 106(4): 550-7.

(27) Lottenberg AMP, Fan PLT, Buonacorso V. Effects of dietary fiber intake on inflammation in chronic diseases. Einstein (São Paulo). 2015; 8(2): 254-8.

(28) Atkinson FS, Foster-Powell K, Brand-Miller JC. International tables of glycemic index and glycemic load values: 2008. Diabetes Care. 2008; 31(12): 2281-3.

(29) Geliebter A, Lee MIC, Abdillahi M, Jones J. Satiety following intake of potatoes and other carbohydrate test meals. Ann Nutr Metab. 2013; 62(1): 37-43.

(30) Andersen SSH, Heller JMF, Hansen TT, Raben A. Comparison of Low Glycaemic Index and High Glycaemic Index Potatoes in Relation to Satiety: A Single-Blinded, Randomised Crossover Study in Humans. Nutrients. 2018; 10(11): 1726.

(31) Akilen R, Deljoomanesh N, Hunschede S, Smith CE, Arshad MU, Kubant $R$, et al. The effects of potatoes and other carbohydrate side dishes consumed with meat on food intake, glycemia and satiety response in children. Nutr Diabetes [Internet]. 2016; 6(2): e195-8. Available from: http://dx.doi.org/10.1038/ nutd.2016.1

(32) Blundell J, De Graaf C, Hulshof T, Hebb S, Jebb S, Livingstone $B$, et al. Appetite control: methodological aspects of the evaluation of foods. Obes rev. 2010; 11(3): 251-70. 